\title{
Increased extracellular signal regulated kinases phosphorylation in the adrenal gland in response to chronic ACTH treatment
}

\author{
Jorge G Ferreira ${ }^{1,3}$, Célia D Cruz ${ }^{2,3}$, Delminda Neves ${ }^{1,3}$ and Duarte Pignatelli ${ }^{1,3,4}$ \\ ${ }^{1}$ Laboratory of Molecular Cell Biology, ${ }^{2}$ Institute of Histology and Embryology, Faculty of Medicine of Porto, Porto, Portugal \\ ${ }^{3}$ Instituto de Biologia Molecular e Celular (IBMC), Porto, Portugal \\ ${ }^{4}$ IPATIMUP Porto Portugal \\ (Requests for offprints should be addressed to D Pignatelli; Email: dpignatelli@yahoo.com)
}

\begin{abstract}
ACTH released from the pituitary acts through activation of cAMP/PKA in adrenocortical cells stimulating steroidogenesis. Although ACTH was originally thought to have antiproliferative effects on the adrenal, recently it has been described that it could also have proliferative effects acting through other signalling cascades. This is also relevant in humans given the increased levels of ACTH occurring together with adrenal cortex hyperplasia observed in Cushing's disease and possibly in other situations such as chronic stress. One of the signalling pathways regulating cell proliferation is the extracellular signal regulated kinase (ERKs) pathway. ERKs are members of the MAPK family of cascades. They are activated by extracellular stimuli such as growth factors and mitogens, become phosphorylated through MEK1/2 and regulate a diversity of cellular processes such as proliferation and differentiation. Until now, no study addressed the effects of chronic ACTH administration on the activation of ERKs in vivo. Using rats submitted to different ACTH dosages as well as
\end{abstract}

variable durations, we determined if ACTH induced ERKs activation and by establishing a parallelism with proliferating cell nuclear antigen (PCNA) expression, we aimed to demonstrate a role of ACTH-induced ERKs activation in cell proliferation. Blood was collected for hormonal analysis and the role of ACTH-induced ERKs activation in the stimulation of steroidogenesis was also studied. We confirmed that ACTH increased adrenal weight and corticosterone levels when compared with control or dexamethasone-treated animals. We also demonstrated that ACTH increases ERKs activation and PCNA expression in a time- and dosedependent manner. When ERKs activation was blocked by the use of a specific MEK inhibitor (PD98059), there was a decrease in ACTH-induced corticosterone release and PCNA expression. We conclude that chronic ACTH induces ERKs activation and that this plays an important role in the induction of cell proliferation as well as steroidogenesis.

Journal of Endocrinology (2007) 192, 647-658

\section{Introduction}

Adrenocorticotrophic hormone (ACTH) is a proopiomelanocortin (POMC)-derived peptide that is synthesized in the anterior pituitary in response to hypothalamic corticotrophin-releasing hormone $(\mathrm{CRH})$. It acts mainly upon the inner zones of the adrenal cortex - zonae fasciculata (ZF) and reticularis (ZR), while having a moderate effect upon zona glomerulosa (ZG) and capsular (Cap) cells (Fujita et al. 1979, Tait et al. 1980, Lehoux et al. 1998, Pignatelli et al. 2002).

ACTH effects on adrenal steroidogenesis have been well documented (Davis \& Garren 1968, Krueger \& Orme-Johnson 1983). The ACTH receptor represents a classical example of a G-protein coupled receptor (GPCR). After binding to its specific receptor on the cell membrane, ACTH leads to an increase in cAMP levels and activation of protein kinase A (PKA; Seelig \& Sayers 1973, Cooke 1999). As a consequence, there is a direct regulation of the biosynthesis of some steroidogenic enzymes such as $\mathrm{P} 450$ cholesterol side-chain cleavage (P450scc), 11 $\beta$-hydroxylase (CYP11B) or steroid dehydrogenase $3 \beta \mathrm{HSD}$ and also some transport proteins such as the steroidogenic acute regulatory protein (StAR; DiBartolomeis \& Jefcoate 1984, Clark et al. 2001, Sewer \& Waterman 2003, Vinson 2003).

On the other hand, ACTH-mediated adrenal proliferation is still debatable. There have been reports that ACTH can induce increased proliferation, particularly under stress conditions (Lotfi \& Armelin 1998, Pignatelli et al. 2002). Notably, adrenocortical hyperplasia can occur after prolonged ACTH exposure in patients suffering from pituitary tumours producing $\mathrm{ACTH}$, a situation known as Cushing's disease (CD; McNicol 2000, Imaki et al. 2004). However, it must not be ruled out that other POMC-derived peptides could be responsible for such effects on adrenocortical hyperplasia (Bicknell et al. 2001, Fassnacht et al. 2003).

Recent in vitro studies involving extracellular signal regulated kinases (ERKs) have begun to clarify the 
participation of these kinases not only in the regulatory mechanisms of adrenal function, particularly in steroid hormone synthesis, but also their pro-proliferative effects (Watanabe et al. 1997, Gyles et al. 2000, 2001, Le \& Schimmer 2001, Bey et al. 2003). ERKs are members of the mitogenactivated protein kinases (MAPK) family of cascades. They are activated by extracellular stimuli such as growth factors or mitogens through Ras/Raf and become phosphorylated through MEK1/2 (Robinson \& Cobb 1997, Volmat \& Pouysségur 2001). They then regulate cell proliferation and/ or differentiation by phosphorylating transcription factors such as CREB or Elk-1 and induce gene expression (Vanhoutte et al. 1999, Murphy et al. 2002).

Work done so far has focused mostly on MAPK activation by ACTH or FGF2 in the Y1 adrenocortical tumour cell line (Le \& Schimmer 2001). It has been reported that ACTH can activate JNK (another MAPK) both in vitro and in vivo, while inhibiting ERKs activation (Watanabe et al. 1997) and also that ACTH induces the expression of MAPK phosphatase-1 (MKP-1) in a PKA-dependent manner (Bey et al. 2003). These studies prove that the ERKs cascade may crosstalk with other signalling pathways in the adrenal, creating a complex web of connections between the different pathways as has been shown for other situations (Gutkind 1998, Stork \& Schmitt 2002). It has also been demonstrated independently that ACTH and ERKs play an important role in regulating steroid secretion, partly by regulating the transcription of the StAR gene (Gyles et al. 2000, 2001, Lehoux et al. 2003).

In the present study, we analyzed the effects of acute or continued administration of ACTH upon ERKs activation and PCNA expression in vivo and if these effects were doseand time-dependent. This may contribute not only to the understanding of how chronic ACTH production (such as in chronic stress situations) can alter adrenal cell function but also correlate these findings with the development of CD related adrenal hyperplasia.

\section{Materials and Methods}

\section{Reagents}

ACTH was obtained as a synthetic 1-24-corticotrophinSynacthen Depôt $(1 \mathrm{mg} / \mathrm{ml})$ - from Novartis, Portugal. Dexamethasone (Decadron - Dxm) solution $(5 \mathrm{mg} / \mathrm{ml})$ was obtained from Merck, Sharp and Dohme, Portugal. Mouse anti-PCNA monoclonal antibody (clone PC10) was obtained from Novocastra Laboratories, UK. Rabbit polyclonal antibody against the phosphorylated forms of ERKs 1 and ERKs 2 (Thr202/Tyr204; phosphoERKs) and total ERKs were purchased from Cell Signalling Technology, UK. 3, 3'-Diaminobenzidine (DAB) was obtained from Sigma Chemicals. PD98059 was purchased from Calbiochem, UK, already dissolved in DMSO and was further diluted in saline to obtain a concentration of $100 \mu \mathrm{g} / \mathrm{kg}$ body weight. The avidinbiotin complex $(\mathrm{ABC})$ and the polyclonal swine anti-rabbit biotin-conjugated secondary antibody were from DAKO, Denmark. ECL Advance kit was purchased from Amersham Biosciences. RIA kits for ACTH ${ }^{25-29}$ and corticosterone $\left({ }^{125} \mathrm{I}-\right.$ labelled) were purchased from DiaSorin (USA) and Immunodiagnostics Systems (IDS) Ltd, UK respectively.

\section{Animals}

Groups of male Wistar rats from IBMC colony, Porto, Portugal, weighing 300-400 g were used as described below. All experiments were carried out according to the Directive of 24 November 1986 (86/609/EEC) of the European Communities Council involving the use of laboratory animals. All animals were killed by decapitation without the use of anaesthetics and all efforts were made in order to minimize animal stress and suffering.

\section{Dose-response study}

Five groups of six animals each were daily injected intraperitoneally (i.p.) with Synacthen Depôt (ACTH) in doses similar to those used in previously published papers (Pudney et al. 1984, Watanabe et al. 1997, Almeida et al. 1998, Neves et al. 2000, Thomas et al. 2004), as well as with higher doses. In brief, animals were injected with ACTH $0 \cdot 2 \mathrm{IU} / 100 \mathrm{~g}$ body weight (b.w.) (ACTH1), ACTH $2 \mathrm{IU} / 100 \mathrm{~g}$ b.w. (ACTH2), ACTH 2 IU/100 g b.w. twice a day (morning and afternoon) (ACTH3), or ACTH $20 \mathrm{IU} / 100 \mathrm{~g}$ b.w. (ACTH4) once a day for three consecutive days. Other groups of animals were also daily injected i.p. with dexamethasone $0.4 \mathrm{mg} / 100 \mathrm{~g}$ b.w. (Dxm) or with saline (controls) once a day for 3 days and used as controls. All animals were sacrificed $24 \mathrm{~h}$ after the last injection.

\section{Time-course study}

Six groups of male Wistar rats ( $n=6$ per group) were used, subjected to a protocol adapted from Neves et al. (2000). The first three groups of rats were injected i.p. with ACTH 2 IU/ $100 \mathrm{~g} \mathrm{b.w.} \mathrm{as} \mathrm{reported} \mathrm{in} \mathrm{previously} \mathrm{published} \mathrm{papers}$ (Almeida et al. 1998, Neves et al. 2000) and killed $30 \mathrm{~min}$, 2, 18 and $24 \mathrm{~h}$ after ACTH administration. In addition, two other groups were injected daily with ACTH 2 IU/100 g b.w. for 3 and 15 days, with animals being killed $24 \mathrm{~h}$ after the last injection. Corresponding control groups were obtained using saline-injected animals.

\section{ERK inhibition with PD98059}

After testing for 100 and $500 \mu \mathrm{g} / \mathrm{kg}$ b.w. of PD98059, the lower dose was chosen since we observed no difference between the two treatments (results not shown). Three groups of Wistar rats ( $n=6$ per group) were treated as follows: one group was injected daily i.p. with PD98059 $100 \mu \mathrm{g} / \mathrm{kg}$ b.w. for 3 days (PD); another group was injected sequentially with ACTH 2 IU/100 g b.w. and PD98059 $100 \mu \mathrm{g} / \mathrm{kg}$ b.w. 
for 3 days (A + PD 3d; both groups were killed $24 \mathrm{~h}$ after the last injection). The last group was given one injection of ACTH 2 IU/100 g b.w. and another injection of PD98059 $100 \mu \mathrm{g} / \mathrm{kg}$ b.w., $30 \mathrm{~min}$ prior to sacrifice (A+PD $30 \mathrm{~min}$ ).

\section{Sample preparation and hormonal analysis}

After sacrifice by decapitation, trunk blood was collected and, after refrigerated centrifugation, plasma was kept at $-80{ }^{\circ} \mathrm{C}$ for ACTH and corticosterone analysis by RIA, according to the manufacturer's protocol.

The adrenals were collected and fixed (4 h) in a solution $4 \%$ paraformaldehyde with $14 \%$ picric acid and embedded in paraffin. Sections, 5- $\mu \mathrm{m}$ thick were mounted in poly-L-lysine covered microscope slides for subsequent processing.

\section{Adrenal morphometry}

For morphometric tests, $5-\mu \mathrm{m}$ thick paraffin sections of the equatorial part of the adrenal with complete cortex and medulla were chosen. Analysis of adrenal sections was performed with the use of ImageJ v1.34 software. The total number of adrenal cells was counted in each slide for ZG, ZF and $\mathrm{ZR}$ in a minimum of four adrenal sections. The volume was then calculated using the area of each zone. Given that adrenocortical cells are mononucleated, the numerical density of the nuclei corresponds to the number of adrenal cells per cubic millimetre. For each section, it was also possible to determine the cellular volume based on the numerical density and the volume of the section, following a method previously described (Almeida et al. 2004).

\section{Immunohistochemistry}

The sections were immunoreacted with polyclonal antibody against phosphoERKs. Briefly, sections were incubated for $10 \mathrm{~min}$ in a solution of $3 \%$ hydrogen peroxide in methanol. After thorough washing in PBS, they were heated for $1 \mathrm{~min}$ with citrate buffer followed by $10 \mathrm{~min}$ at low temperature, for antigen retrieval. The sections were then allowed to cool down to room temperature and subsequently covered with a solution 5\% normal goat serum (NGS) in PBS for $1 \mathrm{~h}$ at room temperature. Sections were incubated for $24 \mathrm{~h}$ at $4{ }^{\circ} \mathrm{C}$ with specific antiserum against phosphoERKs (1:200) diluted in $5 \%$ NGS in PBS. After washing, they were incubated with polyclonal swine anti-rabbit biotin-conjugated antibody (1:200). Immunoreaction was visualized using the $\mathrm{ABC}$ method and DAB as a chromogen. Afterwards, they were counterstained with haematoxylin for $15 \mathrm{~s}$ and mounted with Entellan. Appropriate controls without primary antibody incubation were also performed and no immunoreaction was observed in these circumstances.

Another set of sections from all groups were immunoreacted with specific antiserum against PCNA (1:200), and similarly incubated with the appropriate biotin-conjugated secondary antibody and developed using the ABC complex and $\mathrm{DAB}$ as a chromogen. They were also counterstained with haematoxylin for $15 \mathrm{~s}$ and mounted with Entellan.

\section{Western blot}

Thirty micrograms protein of each sample were loaded into a $12 \%$ SDS-polyacrylamide gel and allowed to run for $2 \mathrm{~h}$. After electrophoresis, separated peptides were transferred to a nitrocellulose membrane for $2 \mathrm{~h}$. Nitrocellulose membranes were incubated for $1 \mathrm{~h}$ with blocking solution (5\% dried nonfat milk with $0 \cdot 1 \%$ Tween 20 in Tris buffer saline - TBS) and immunoreacted either with specific antiserum against phosphoERKs, total ERKs or actin for $24 \mathrm{~h}$ at $4{ }^{\circ} \mathrm{C}(1: 1000)$. After extensive washing, the membranes were incubated with a secondary antibody coupled to horseradish peroxidase for $1 \mathrm{~h}$ and labelled bands were evidenced using the ECL Advance kit. Analysis of the western blot (WB) was done using the ScionImage software version beta 4.0.3. Analysis of ERKs activation was done by calculating the ratio between phosphoERKs and total ERKs. Normalization of total ERKs was performed using actin as an internal control. Results represent the relative increase in each of the phosphoERKs for each treatment group as compared with controls.

\section{Immunoreactive cells quantification}

PhosphoERKs immunoreactive (IR) cells were counted in Cap, ZG, ZF and ZR in at least four different adrenal sections from each animal under a $20 \times$ objective lens in a Nikon microscope (Optiphot model) using the slides processed by the ABC method. PCNA-positive nuclei were counted in Cap, ZG, ZF and ZR cells in at least four adrenal sections from each animal under the same conditions as stated above, using the slides processed by the ABC method.

\section{Statistical analysis}

Results are presented as means \pm s.D. Statistical significance was determined by ANOVA. Differences were determined using a post hoc Student-Newman-Keuls test and were considered significant when $P<0 \cdot 05$. All significances are determined versus control values except where indicated.

\section{Results}

\section{ACTH effects on adrenal gland weight and hormone secretion}

We observed an increase in the mean adrenal weight (mg/100 g b.w. - AW) in the ACTH2, ACTH3 and ACTH4 groups $(P<0.05$ for all groups), and in the ACTH24h, ACTH3d and ACTH15d groups $(P<0 \cdot 05$ for all groups) when compared with controls (Fig. 1A and C). The AW from ACTH1, ACTH30min, ACTH2h and ACTH18h groups were not different from controls. The Dxm group showed a significant decrease in AW when 

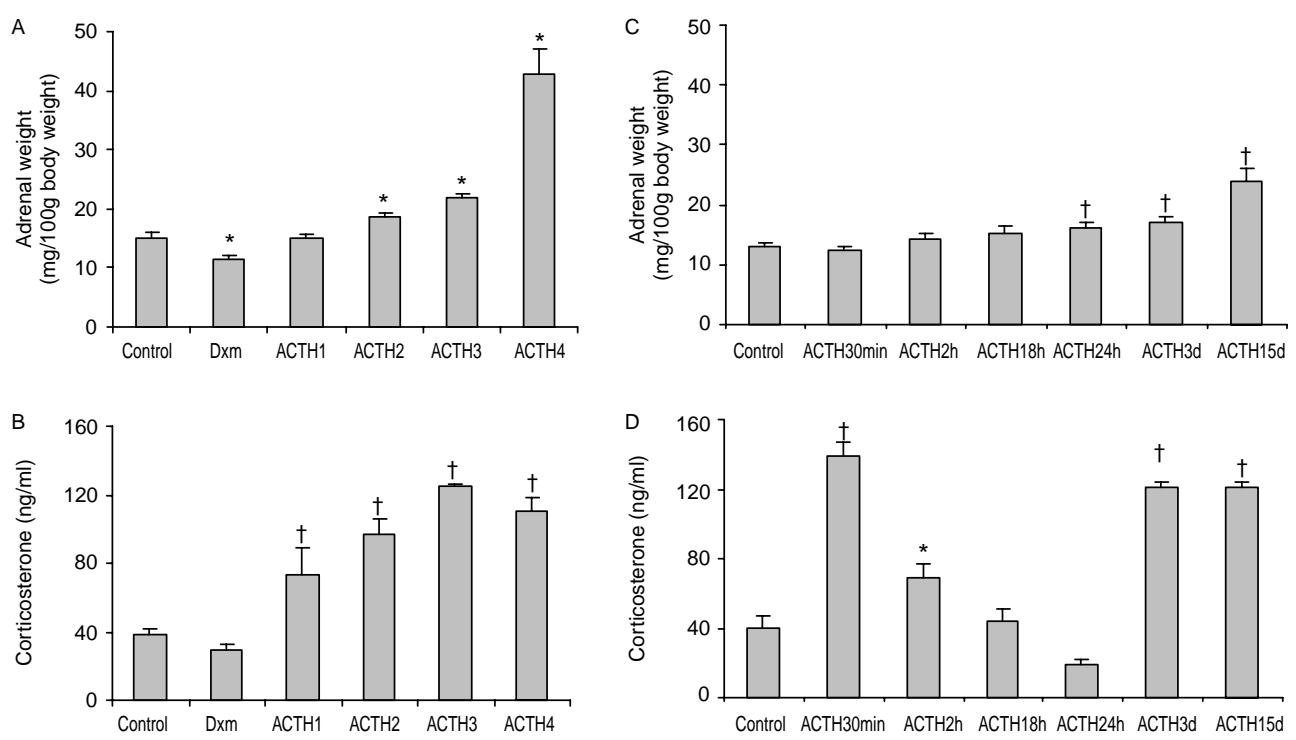

Figure 1 Adrenal weight/100 g body weight and hormonal analysis. Results of the dose-response experiment $(A$ and $B)$ and the time-course experiment (C and D). Adrenal weight increased after $24 \mathrm{~h}$ of $A C T H$ treatment as well as from the ACTH2 group onwards. Corticosterone increases significantly after $30 \mathrm{~min} \mathrm{ACTH}$ treatment $(P<0 \cdot 001$ vs control) and decreases thereafter until $24 \mathrm{~h}$. After that, it increases at 3 days, remaining elevated at 15 days of ACTH treatment $(P<0 \cdot 001$ vs control). All results are presented as means \pm s.D. ${ }^{*} P<0 \cdot 01 ;{ }^{\dagger} P<0 \cdot 001$.

compared with controls $(10 \cdot 50 \pm 0 \cdot 2$ and $14 \cdot 74 \pm 0 \cdot 8$ respectively; $P<0 \cdot 001$, Fig. $1 \mathrm{~A})$. In the dose-response experiment, we observed a significant increase in plasma corticosterone in all ACTH-treated groups when compared with controls $(38 \cdot 00 \pm 10 \cdot 8 \mathrm{ng} / \mathrm{ml})$ or Dxm groups $(28 \cdot 91 \pm$ $10.6 \mathrm{ng} / \mathrm{ml} ; \quad P<0 \cdot 001$, Fig. 1B). Regarding the ACTH measurements, no differences were observed in Dxm-treated animals $(28.00 \pm 8.3 \mathrm{pg} / \mathrm{ml})$ when compared with the controls $(39 \cdot 33 \pm 17 \cdot 9 \mathrm{pg} / \mathrm{ml})$. The same was also observed in all ACTH-treated groups, which were not different from controls. This resulted from the fact that ACTH dosage was performed with a RIA kit specific for the ACTH ${ }^{25-39}$ peptide that therefore was unable to detect the injected ACTH ${ }^{1-24}$ peptide. Thus, the levels measured were the endogenous levels of ACTH.

In the time-course experiment, we observed a peak in corticosterone values for the ACTH30min group (140.50 \pm $17 \cdot 3 \mathrm{ng} / \mathrm{ml} ; P<0 \cdot 001)$. The values remained elevated in the ACTH2h group $(70 \cdot 19 \pm 7 \cdot 9 \mathrm{ng} / \mathrm{ml}, P<0 \cdot 01)$, but decreased over time until the ACTH24h group. The ACTH3d and ACTH15d groups also presented elevated values of corticosterone $(123 \cdot 00 \pm 2 \cdot 1$ and $122 \cdot 53 \pm 3 \cdot 3 \mathrm{ng} / \mathrm{ml}$ respectively; $P<0 \cdot 001)$ when compared with controls $(40.84 \pm$ $11.2 \mathrm{ng} / \mathrm{ml}$, Fig. 1D), but these were, not as high as the ACTH30min group. These results represent an adaptation of the organism to the ACTH stimulation in chronic situations. Even when normalized for the total number of adrenal cells, the variations in corticosterone were similarly increased, showing that there was an effective increase in hormone secretion (data not shown).

Regarding ACTH determinations, all animals presented values similar to controls, except the ACTH18h group, which had an increased ACTH value $(142 \cdot 10 \pm 42 \cdot 1 \mathrm{pg} / \mathrm{ml}$, $P<0 \cdot 001)$.

\section{ACTH increases adrenal cell volume and proliferation}

The results of the morphometric tests are summarized in Fig. 2. ACTH induced an increase in the mean adrenal cell volume (Fig. 2A and C) and an adrenal cell hyperplasia (Fig. 2B and D). All ACTH groups in the dose-response experiment had increased cell volume, with the largest increase achieved in the ACTH4 group (1132.88 \pm $314.0 \mu^{3}, P<0 \cdot 05$; Fig. $2 \mathrm{~A}$ ). The treatment with Dxm did not change mean adrenal cell volume when compared with controls $\left(446 \cdot 14 \pm 31 \cdot 1\right.$ and $427 \cdot 72 \pm 24 \cdot 0 \mu^{3}$ respectively; Fig. 2A). For the time-course experiment, the increase in mean adrenal cell volume started as early as $30 \mathrm{~min}$ $\left(668 \cdot 29 \pm 19 \cdot 4 \mu^{3}, P<0 \cdot 01\right.$; Fig. 2C) after ACTH administration. After $2 \mathrm{~h}$ of $\mathrm{ACTH}$, the cell volume decreased $\left(583 \cdot 46 \pm 55 \cdot 7 \mu^{3}\right.$ for the ACTH2h group and 648.04 \pm 84.4 for the ACTH18h group). However, with $24 \mathrm{~h}$ of ACTH administration, cell volume increased again $(942 \cdot 77 \pm$ $219.5, P<0.05)$ and remained elevated throughout the experiment until the 15 -day treatment $\left(752.59 \pm 54.7 \mu \mathrm{m}^{3}\right.$, $P<0 \cdot 01$; Fig. 2C). 

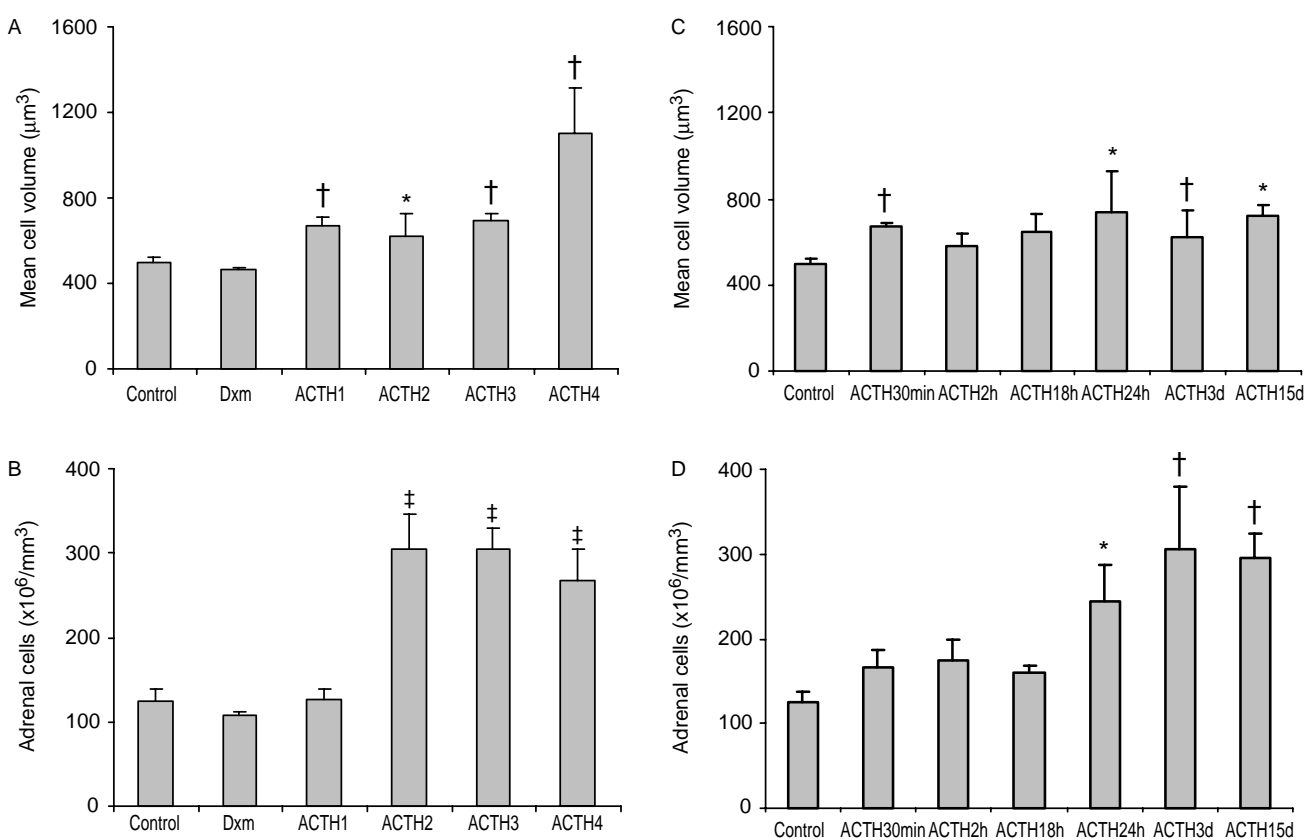

Figure 2 Adrenal cell volume and cell number after treatment with ACTH or dexamethasone at different doses and times. Results for the dose-response experiment (A and B) and the time-course experiment (C and D). Adrenal volume and cell number increased after ACTH treatment. Increase in adrenal cell volume occurs earlier than adrenal hyperplasia in the time-course experiment. All results are presented as mean \pm s.D. ${ }^{*} P<0 \cdot 05 ;{ }^{\dagger} P<0 \cdot 01 ;{ }^{\mp} P<0 \cdot 001$.

The number of adrenal cells per cubic millimetre was also estimated for each zone of all treatment groups. We verified that, in parallel with adrenal hypertrophy, ACTH also induced adrenal hyperplasia. However, unlike the previous, hyperplasia was only observed for higher ACTH doses $(P<0.05$ for ACTH2, ACTH3 and ACTH4 groups when compared with controls; Fig. 2B and D) or longer treatments with ACTH (i.e. longer that $24 \mathrm{~h}$ ), which presented a significantly higher number of adrenal cells per cubic millimetre $(P<0.05$ for ACTH24h, ACTH3d and ACTH15d groups when compared with controls). This hyperplasic effect was observed mainly in ZF and ZR. For shorter treatments ( 2 and $18 \mathrm{~h}$ of $\mathrm{ACTH})$, or treatments with lower doses (ACTH1), there was no increase in adrenal cell numbers. This observation is in accordance with the fact that adrenal weight increases only after a 24-h ACTH treatment.

\section{Activation of ERKs by ACTH in the adrenal gland is dose- dependent}

In the adrenals from controls and Dxm-treated animals very few phosphoERKs IR cells could be observed $(72 \cdot 75 \pm 8 \cdot 9$ and $59 \cdot 26 \pm 9 \cdot 8$ respectively). The difference between these two groups was not significant (Figs $3 \mathrm{~A}$ and $4 \mathrm{~A}$ ). In the ACTH1 group, we could observe a slight increase in phosphoERKs IR cells $(144 \cdot 19 \pm 4 \cdot 3$; Fig. 4A). The increase was not significant when we considered the whole adrenal, but was significant both for Cap and ZG cells $(P<0 \cdot 001)$. The number of phosphoERKs IR cells was more pronounced in the ACTH2 and ACTH3 groups. In ACTH2 group, the total number of phosphoERKs IR cells was $302 \cdot 04 \pm 13 \cdot 0$, while in the ACTH3 group it was $327 \cdot 77 \pm 13 \cdot 1(P<0 \cdot 001$ vs controls). Between these two groups the difference was not significant (Figs $3 \mathrm{~A}$ and $\mathrm{B}$ and $4 \mathrm{~A}$ ). In the ACTH4 group, there was an even higher increase in the number of phosphoERKs-positive cells $(746 \cdot 45 \pm 37 \cdot 9)$, which was significant when compared with any of the other groups (Figs 3G and 4A, P<0.001). With the InZA antibody, following a protocol described previously (Barker et al. 1992), we were able to show that in the ACTH4 group, in spite of a great architectural disruption, adrenal cortex zonation still maintained original characteristics, namely the presence of a stained ZF and ZR and an unstained ZG (not shown). Overall, the increase in phosphoERKs-positive cell numbers was higher in ZF, which is consistent with the fact that these cells are more responsive to ACTH.

Capsular staining increased with ACTH treatment intensity especially with the highest concentrations (20 IU/100 g b.w.). Also, phosphoERKs were always detected in the ZG of ACTHtreated animals, but were very low in the ZG of control or Dxm animals (Fig. 3A and B). All groups had strong phosphoERK immunostaining in the medulla, including saline-treated animals, and this was used as a positive control since it did not vary during the experiments (Fig. $3 \mathrm{H}$ ). In addition, ACTH also activated ERKs in endothelial cells of all ACTH-treated groups, including the low-dose ACTH stimulation (ACTH1), a fact that did not occur in controls or Dxm groups (Fig. 3). 


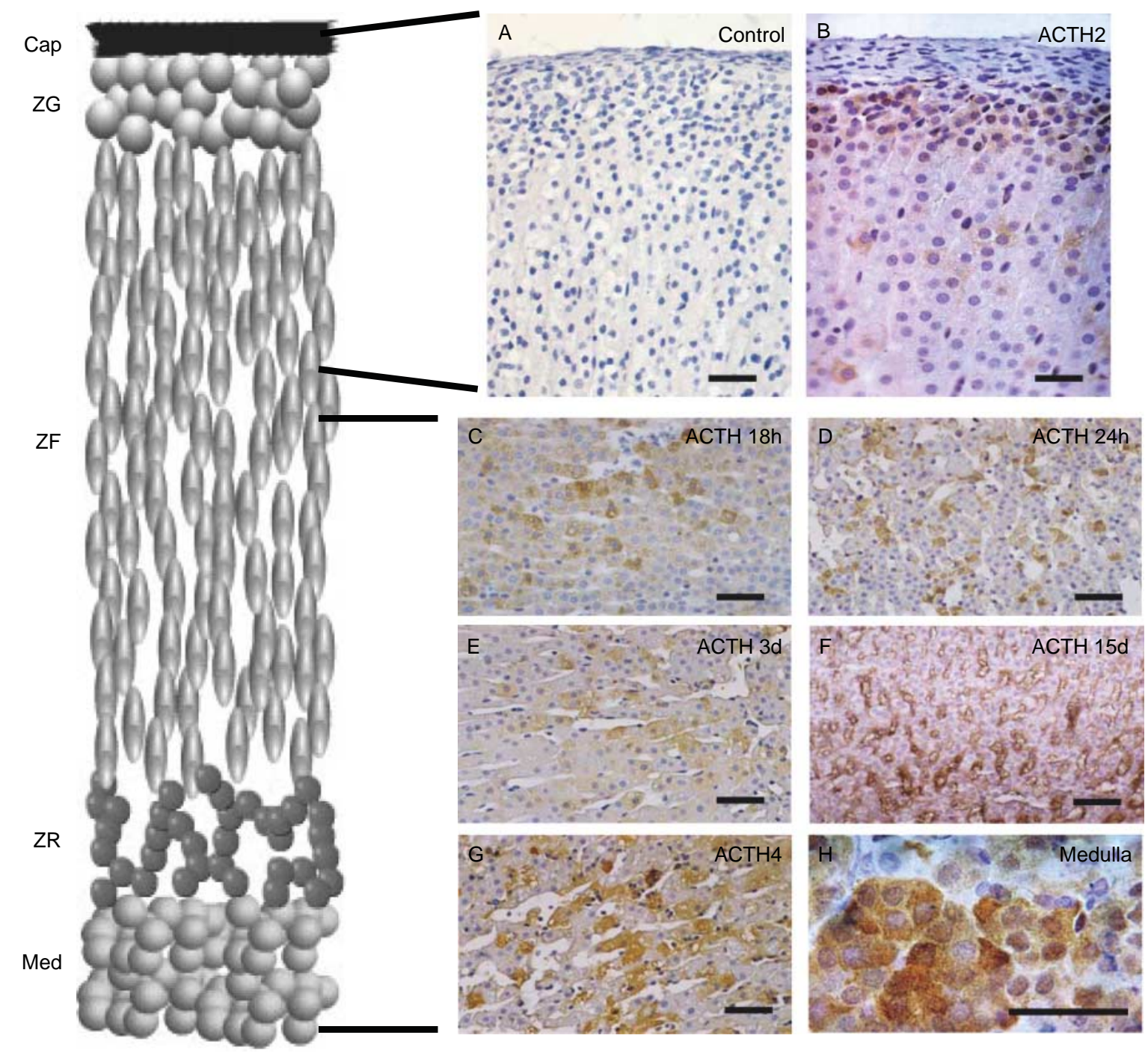

Figure 3 Adrenal glands from control and ACTH-treated animals immunostained for phosphoERKs. Adrenal sections from controls (A), ACTH2 (B) and ACTH4 (G) animals. Notice the increased number of immunoreactive (IR) cells in ZF and the diffuse staining in ZG in the ACTH-treated animals when compared with controls. Adrenal sections from ACTH18h (C), ACTH24h (D), ACTH3d (E) and ACTH15d (F) animals. Notice the phosphoERK IR cells dispersed through the inner zones of the adrenal, especially in ZF and ZR. A detail from the medulla (Med) cells is shown in $(\mathrm{H})$, which presented strong immunostaining all groups including control and Dxm. Endothelial cells showed intense staining in all ACTH-treated groups but not in control or Dxm (A-G). Scale bars represent $50 \mu \mathrm{m}$ in all photomicrographs, except in B and $\mathrm{H}$, in which they represent $10 \mu \mathrm{m}$.

The increase in ERKs activation by ACTH was further analyzed by WB and is presented in Fig. 5A. Confirming the immunohistochemical results, there was a significant increase in the overall quantity of phosphoERKs in the ACTH2 $(363 \cdot 63 \pm 46 \cdot 3 \%$ for ERK1 and $219 \cdot 66 \pm 17 \cdot 4 \%$ for ERK2, $P<0.001$ and $<0.01$ respectively) and ACTH4 groups $(341 \cdot 08 \pm 30 \cdot 8 \%$ for ERK1 and $259 \cdot 48 \pm 31 \cdot 8 \%$ for ERK2, $P<0.001$ for each), when compared with controls. In the Dxm-treated and ACTH1 groups, the amount of phosphoERKs was not significantly different when compared with controls. Total ERK did not vary among any of the experimental groups, including controls.
Activation of ERKs by ACTH in the adrenal gland is time-dependent

We observed a peak in the total number of phosphoERKs IR cells in the ACTH30min group $(250 \cdot 85 \pm 24 \cdot 2 ; P<0 \cdot 01)$. Afterwards, there was a decrease in the number of positive cells $(174.45 \pm 15.0$ for ACTH2h and $221.61 \pm 12.5$ for the ACTH18h group) but they were still significantly higher than controls $(87 \cdot 88 \pm 20 \cdot 63$; Figs $3 \mathrm{C}$ and $4 \mathrm{C} ; P<0 \cdot 001)$. The increase in phosphoERKs was even more pronounced in the ACTH24h (293.12 $\pm 15 \cdot 49, P<0 \cdot 001)$, ACTH3d (302.04 \pm 13.0, $P<0 \cdot 001)$ and the chronic 15-day ACTH treatment 

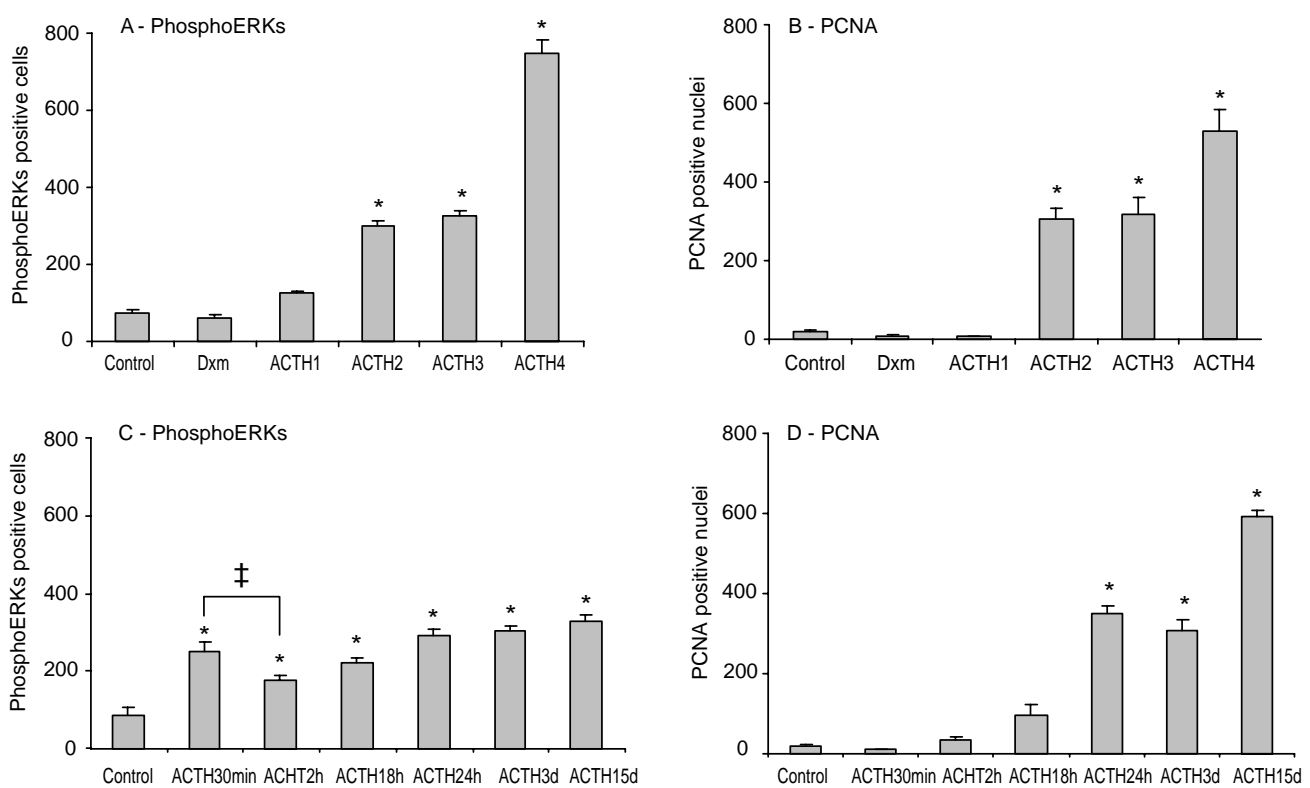

Figure 4 Number of phosphoERKs immunoreactive (IR) cells and PCNA-positive nuclei for the dose-response $(A$ and $B)$ and time-course (C and D) experiments. Statistically significant differences were observed between controls and ACTH2, ACTH3 and ACTH4 groups as well as between ACTH3 and ACTH4 groups. No differences were found between controls and Dxm or the ACTH1 group. In the time-course experiment, phosphoERKs showed a significant increase in all ACTH-treated groups when compared with controls. All results are presented as means \pm S.D. ${ }^{*} P<0 \cdot 001 ;{ }^{\ddagger} P<0 \cdot 05$.

$(326 \cdot 83 \pm 18 \cdot 48, P<0 \cdot 001)$ in comparison with controls (Figs 3D-F and 4C). No significant difference was found between these groups. This increase in phosphoERKs was evident in every adrenal zone when compared with controls as well as in Cap cells. Again, medulla (Med) cells showed very intense IR cells in all groups, including controls (Fig. 3H).

Interestingly, ACTH activated ERKs in endothelial cells as early as $30 \mathrm{~min}$ after treatment, with the staining intensity

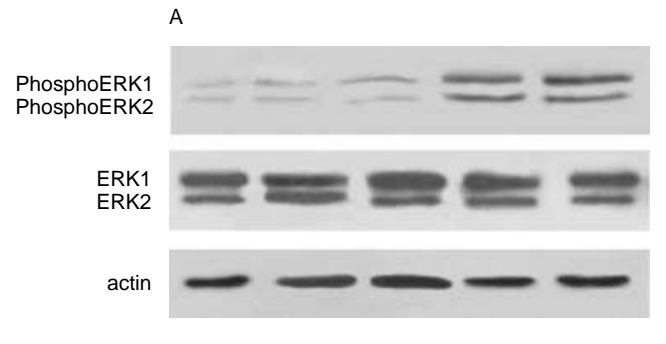

B
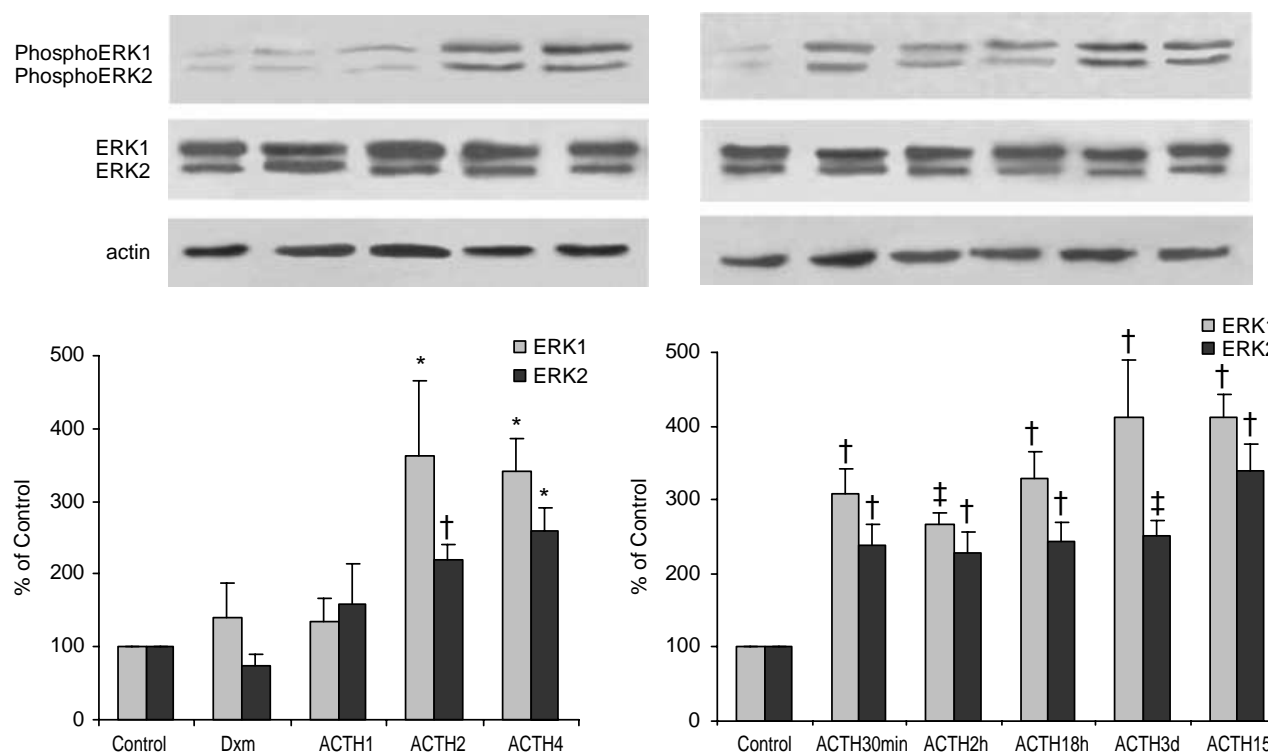

Figure 5 Western blot analysis of phosphoERKs for the dose-response experiment $(A)$ and the time-course experiment (B). Semi-quantitative analysis of phosphoERKs levels showed a significant increase in ERKs activation after ACTH treatment (except for the ACTH1 group), but not the Dxm group. There was also an increase in phosphoERKs levels in all ACTH-treated groups of the dose-response experiment. ${ }^{*} P<0 \cdot 001 ;{ }^{\dagger} P<0 \cdot 01 ;{ }^{\ddagger} P<0 \cdot 05$. 
increasing steadily towards the 15-day treatment group (Fig. 3C-F) although no specific quantification was performed. In the control animals, no phosphoERKs-positive endothelial cells were observed (Fig. 3A).

We also performed a WB analysis of the isolated protein samples from the controls, ACTH30min, ACTH2h, ACTH18h, ACTH3d and ACTH15d groups, for active ERKs and total ERKs (Fig. 5B). The results were in agreement with those obtained by immunohistochemistry. ACTH30min presented a peak in ERK activation $(309 \cdot 23 \pm$ $31 \cdot 8$ for ERK1 and $238 \cdot 71 \pm 27 \cdot 6$ for ERK2; $P<0 \cdot 01$ ). There was a slight decrease in phosphoERKs in the ACTH2h group when compared with control $(267 \cdot 13 \pm 30 \cdot 3 \%$ for ERK1; $P<0 \cdot 05$ and $216 \cdot 96 \pm 25 \cdot 8 \%$ for ERK2; $P<0 \cdot 01)$. ACTH18h group presented $328 \cdot 39 \pm 70 \cdot 3 \%$ for ERK1 $(P<$ $0 \cdot 05)$ and $244 \cdot 79 \pm 39 \cdot 6 \%$ for ERK2 $(P<0 \cdot 01)$. Afterwards, there was another increase in phosphoERKs with ACTH3d group presenting $411.92 \pm 65.5 \%$ for ERK1 $(P<0.01)$ and $251 \cdot 97 \pm 27 \cdot 9 \%$ for ERK2 $(P<0 \cdot 01)$. ACTH15d group had $411 \cdot 25 \pm 55 \cdot 3 \%$ for ERK1 $(P<0 \cdot 005)$ and $340 \cdot 26 \pm 30 \cdot 1 \%$ for ERK2 $(P<0 \cdot 001)$. As for the dose-response experiment, total ERK did not vary in any of the experimental groups.

\section{ACTH induces the expression of PCNA in a dose-dependent manner}

After saline and Dxm treatment very few PCNA-positive nuclei could be observed in any of the adrenal zones $(17 \cdot 86 \pm$ $5 \cdot 8$ and $6 \cdot 87 \pm 3 \cdot 0$ respectively). This was also the case with the ACTH1 group, which presented very few PCNApositive nuclei $(8 \cdot 06 \pm 0 \cdot 5)$. However, after stronger ACTH stimulation the number of IR nuclei dramatically increased, reaching $295 \cdot 56 \pm 27 \cdot 7$ for the ACTH2 treatment, 317.90 \pm $42 \cdot 6$ for the ACTH3 group and $530 \cdot 18 \pm 52 \cdot 2$ for the ACTH4 treatment. The differences between each of the treatment groups and the control group were found to be statistically significant $(P<0 \cdot 001)$. This increase in PCNA immunoreactivity was observed in all adrenal cortex zones and was evident also in Cap cells (see Fig. 4B).

\section{ACTH increases PCNA expression in a time-dependent manner}

Saline-treated animals presented a low number of PCNA IR nuclei $(18 \cdot 76 \pm 5 \cdot 7)$. This number at first did not increase at $30 \mathrm{~min}(10 \cdot 31 \pm 3 \cdot 1)$ or $2 \mathrm{~h}(34 \cdot 97 \pm 9 \cdot 0)$ after ACTH stimulation. However, a gradual increase in IR nuclei was observed after $18 \mathrm{~h}(96 \cdot 95 \pm 24 \cdot 2), 24 \mathrm{~h}(348 \cdot 70 \pm 22 \cdot 3)$ and 3 days $(295 \cdot 56 \pm 27 \cdot 7)$, peaking at the chronic 15-day treatment group $(592 \cdot 45 \pm 15 \cdot 7)$. Significant differences in relation to the control group were found only after the $18 \mathrm{~h}$ ACTH treatment and thereafter (Fig 4D, $P<0 \cdot 001$ ). We verified that PCNA-positive nuclei appeared first in the area between $\mathrm{ZG}$ and $\mathrm{ZF}$ (an area known as zona intermedia - ZI) during earlier time points (18 and $24 \mathrm{~h}$ ) and gradually expanded towards the Cap and ZG, as well as towards inner zones as treatment duration increased. This pattern of response is slightly different from what was observed in the doseresponse experiment, where the ACTH4 group continued to show higher Cap PCNA staining than the inner areas.

Effect of PD98059 administration on steroidogenesis and adrenal proliferation

In order to assess the effects of ERKs activation on the regulation of adrenal proliferation and steroidogenesis induced by ACTH, we treated animals with $100 \mu \mathrm{g} / \mathrm{kg}$ b.w. of PD98059 (a MEK inhibitor). We verified that while PD98059 administration alone did not have any effect upon the adrenal, inhibition of ACTH-induced ERKs activation had profound effects on the adrenal. Treatment with PD98059 lowered the number of phosphoERKs-positive cells from $301.98 \pm 17.6$ in ACTH-treated animals to $42 \cdot 92 \pm 6 \cdot 7$ in animals treated with both ACTH and PD98059 for 3 days $(P<0 \cdot 001$; Fig. 6E). This was also observed in animals treated with both ACTH and ERKs inhibitor for $30 \mathrm{~min}(P<0 \cdot 001$, not shown). Furthermore, by inhibiting ERKs activation, we managed to partially block ACTH-induced proliferation as measured by PCNA staining in chronic ACTH-stimulated animals $(48 \cdot 50 \pm 16 \cdot 6$ positive nuclei for A + PD 3d vs $304 \cdot 04 \pm 29 \cdot 9$ positive nuclei for ACTH-only treatment, $P<0 \cdot 001$; Fig. 6F). This was confirmed after verifying that treatment with both ACTH and the inhibitor did not increase the total number of adrenal cells when compared with controls $\left(526 \cdot 42 \pm 29 \cdot 9 \times 10^{-6}\right.$ cells $/ \mathrm{mm}^{3}$ for controls and $589.79 \pm 31.7 \times 10^{-6}$ cells $/ \mathrm{mm}^{3}$ for A+PD 3d; Fig. 6D), although there was a significant increase in the mean adrenal cell volume $\left(118.02 \mu \mathrm{m}^{3}\right.$ for controls vs $272 \cdot 63 \mu^{3}$ for A + PD $3 \mathrm{~d}$; $P<0 \cdot 01$; Fig. 6C). Curiously, treatment with PD98059 did not produce any changes in the adrenal weight (Fig. 6A).

We also analyzed the capability of PD98059 to reduce corticosterone production by the adrenal following ACTH administration. We verified that treating animals with PD98059 alone had no effects upon the adrenal corticosterone production when compared with control animals (Fig. 6B). However, when animals were treated with ACTH and PD98059 for $30 \mathrm{~min}$, we could not prevent corticosterone production by the adrenal. Curiously, these animals were no different from animals treated with ACTH only for $30 \mathrm{~min}$ $(545 \cdot 0 \pm 78 \cdot 3 \mathrm{ng} / \mathrm{ml}$ for animals with ACTH and PD 98059 for $30 \mathrm{~min}$ when compared with $268 \cdot 9 \pm 68 \cdot 1 \mathrm{ng} / \mathrm{ml}$ for animals injected with ACTH alone for $30 \mathrm{~min}$ ).

In contrast with this, we verified that chronic 3-day treatment with both ACTH and the inhibitor decreased corticosterone levels to values similar to controls when compared with the 3-day ACTH-only treatment (45.63 \pm $18.0 \mathrm{ng} / \mathrm{ml}$ for ACTH + PD98059 3-day treatment group vs $80 \cdot 80 \pm 15 \cdot 0 \mathrm{ng} / \mathrm{ml}$ for ACTH-only treated animals; $P<0 \cdot 05$; Fig. $6 \mathrm{~B}$ ), which strengthens the idea that ERKs activation must play a role in chronic ACTH-induced steroidogenesis. 

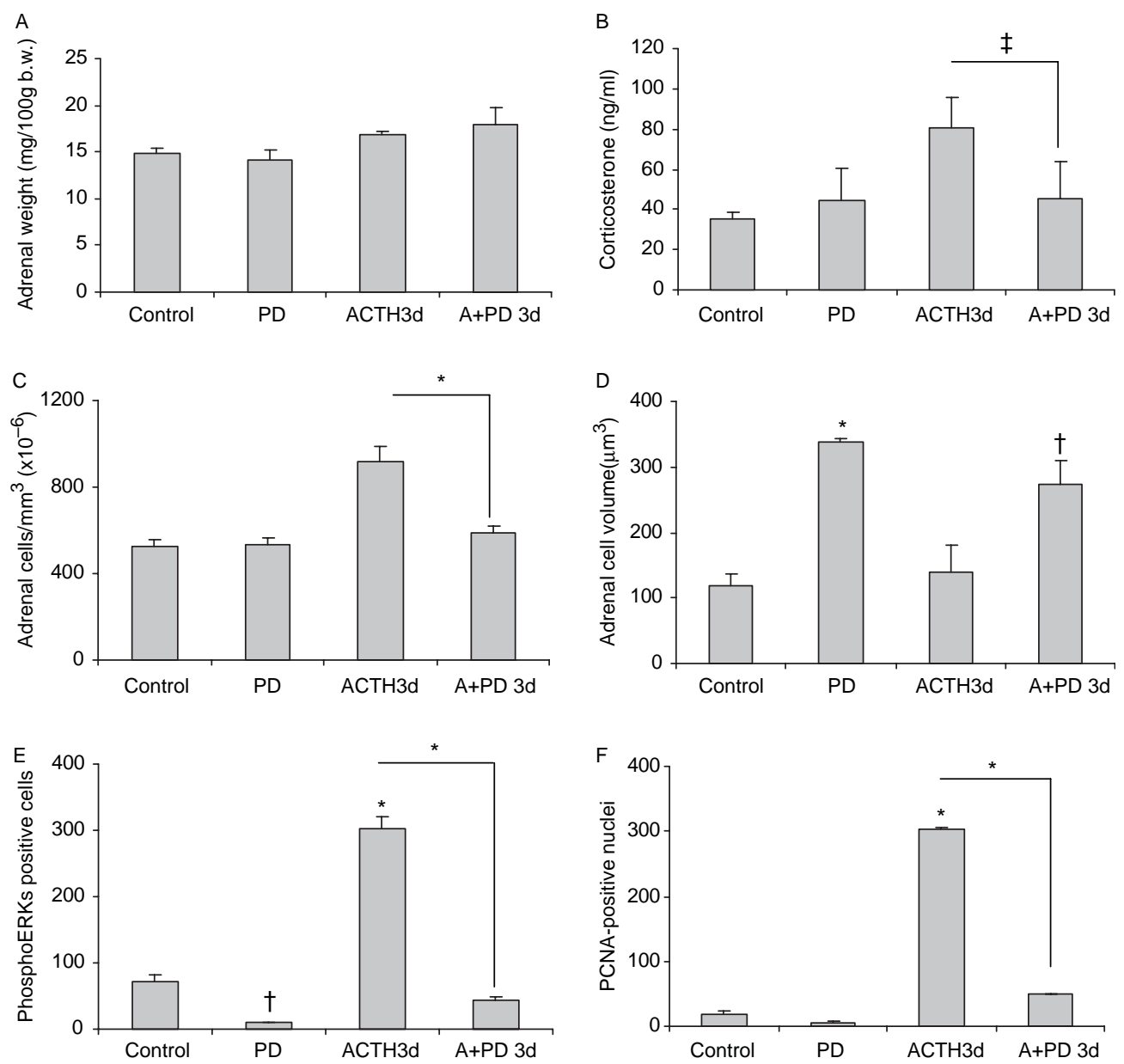

Figure 6 PD98059-induced changes in the adrenal gland. Animals were analyzed for adrenal weight (A), corticosterone production (B), adrenal cell number (C) and adrenal cell volume (D). Corticosterone production and the number of cells per adrenal volume decrease following chronic treatment with ACTH+PD98059 for 3 days in comparison with ACTH treatment alone. The number of phosphoERKs positive cells (E) and PCNA positive nuclei (F) after ERKs inhibition with PD98059, shows a significant decrease when compared with ACTH treatment alone. All results are presented as means \pm s.D. ${ }^{*} P<0 \cdot 001 ;{ }^{\dagger} P<0 \cdot 01 ;{ }^{\ddagger} P<0 \cdot 05$.

\section{Discussion}

In this study, we investigated the effects of $\mathrm{ACTH}$ on the induction of adrenal proliferation and activation of the ERKs signalling pathway. From our observations, we can conclude that ACTH is able to induce a sustained and progressive increase in ERKs activation in adrenocortical cells. This is in accordance with a recent report showing that ERKs activation can occur shortly and gradually following stimulation in a dose-dependent manner (MacKeigan et al. 2005, Winnay \& Hammer 2006).

ERKs are critical components of the MAPK family of cascades involved in the transduction of mitogenic stimuli involving both growth factors and an increasingly known number of hormones (Cameron et al. 1996, Paul et al. 1997). ERKs activation is triggered by MEK1/2-dependent phosphorylation at specific residues on both ERKs (for review see Volmat \& Pouysségur 2001, Johnson \& Lapadat 2002).

Although it was originally proposed that ACTH induced JNK activation and ERKs inhibition (Watanabe et al. 1997), it was recently demonstrated in Y1 adrenocortical cells that both FGF and ACTH (to a lesser extent) induce ERKs activation (Lotfi et al. 2000, Le \& Schimmer 2001). Our study was the first to address the effect of chronic ACTH stimulation on ERKs activation. Our experiments allowed the distinction between acute (up to $24 \mathrm{~h}$ of ACTH) and chronic (24 $\mathrm{h}$ and thereafter) responses to ACTH treatment based on corticosterone production by the adrenal. In this way, we also observed that ERKs activation starts immediately following ACTH injection and can be divided into an acute phase (from 30 min until $18 \mathrm{~h}$ of $\mathrm{ACTH}$ ) and a chronic phase 
(from 24 h to 15 days of ACTH). This later activation could be related to the increased cell proliferation observed in longer treatments but could also play a part in the increased steroidogenic output observed. The occurrence of different peaks in ERKs activation is not surprising since it has been reported that $\mathrm{ACTH}$ induces a cyclic pattern of activation of ERKs as well as of SF-1 (Winnay \& Hammer 2006). Similar to their work, we also observed a peak in ERKs activation at $30 \mathrm{~min}$. However, since we did not perform any intermediate measurement between 2 and $18 \mathrm{~h}$ of ACTH, further studies should be made to assess if there is a cyclical pattern with other peaks throughout the period between 2 and $18 \mathrm{~h}$ after ACTH administration.

It has been generally accepted that ACTH-induced steroidogenesis in the adrenal is mediated by cAMP/PKA, albeit it became clear recently that ACTH action is exerted through the induction and modulation of multiple cellular messengers (Kimura et al. 1993, Gallo-Payet \& Payet 2003). Growing amount of evidence is also implicating ERKs in the steroidogenic process. Recent reports have demonstrated that steroid synthesis mediated by StAR was directly regulated by ERKs, and that ERKs activation is partly dependent on PKA activity (Gyles et al. 2000, 2001). Furthermore, Wu et al. (2002) showed that hyperactive Ras could lead to an increase in steroidogenesis through ERKs activation in human adrenocortical cells. If so, it could be possible that the increase in phosphoERKs might have a role in ACTHinduced corticosterone production. In fact, when PD98059 was injected in a chronic manner, corticosterone production was impaired, implicating ERKs in the chronic steroidogenic process. These results lead us to think that ERKs role may be related to the increased transcription of steroidogenic enzymes as proposed earlier in adrenal (Gyles et al. 2001) and non-adrenal cells (Martinat et al. 2005, Manna et al. 2006). Our group is now performing further studies using ERKs inhibitors in vivo to confirm this point. In agreement with our hypothesis, it should be noted that acute blocking of ERKs activation by PD98059, did not produce any effect upon adrenal steroidogenesis. Accordingly, it has been demonstrated that SF-1 and RNA Pol-II are activated only 40 and 80 min following ACTH administration respectively (Winnay \& Hammer 2006) and therefore, are unable to induce steroidogenic enzyme synthesis only $30 \mathrm{~min}$ after ACTH stimulation.

On the other hand, since ERKs activation does not decrease in parallel with corticosterone levels, we can assume that ERKs play other roles in adrenal regulation. For instance, it would be reasonable to imply that the increase in ERKs activation might be important in controlling adrenal proliferation observed in chronic ACTH stimulations. Expression of a proliferation marker such as PCNA is not up-regulated by acute ACTH or low-dose ACTH, in contrast with ERK activation. In fact, PCNA expression becomes prominent only after long ACTH treatments, when adrenal hyperplasia is observed. Accordingly, we show that the first effect induced by ACTH is hypertrophy of the adrenal cells and that hyperplasia only occurs if the stimulus is maintained long enough. Interestingly, activation of ERKs also increases significantly at the same time as PCNA expression (i.e. after $24 \mathrm{~h}$ of ACTH). One possible explanation might have to do with the fact that the activation/expression of ERKdependent genes occurs in a switch-like manner. Thus, the stimulus has to be strong enough (MacKeigan et al. 2005) or prolonged enough (Murphy et al. 2002) to have such an effect. This would mean that ACTH-driven PCNA expression could only occur if the dose of ACTH is either strong enough or is maintained long enough. Accordingly, no PCNA expression was observed after a prolonged but weak ACTH stimulation $(0 \cdot 2 \mathrm{IU} / 100 \mathrm{~g}$ b.w. for 3 days $)$ or after a strong but short ACTH stimulus ( $<24 \mathrm{~h}$ with 2 IU/100 g b.w.). In fact, when we inhibited ERKs activation by administering a specific MEK inhibitor (PD98059) in vivo, we observed both a decrease in the number of phosphoERKs-positive cells and PCNA-positive nuclei in the adrenal. Nevertheless, it must be noted that other POMC-derived peptides could have an effect on adrenal proliferation as has been suggested previously (Bicknell et al. 2001, Fassnacht et al. 2003). This warrants further studies on the possible regulation of adrenal proliferation through the ERKs cascade.

We verified that proliferation started to occur in the outer zones of the gland, particularly in the zona intermedia, between $\mathrm{ZG}$ and $\mathrm{ZF}$. This happened at around $18 \mathrm{~h}$ after ACTH stimulation, progressing afterwards towards the ZG and the inner zones at later time-points. This is in agreement with the previous reports by Mitani et al. (2003), which show that the ZI is the main proliferative area of the adrenal. Our data also indicate that the larger number of cells possibly in division occurs at $24 \mathrm{~h}$ and thereafter. Such results could explain the increase in adrenal weight and hyperplasia occurring around $24 \mathrm{~h}$ after ACTH stimulation and thereafter. Curiously the major increase in adrenal cells is observed in ZF, where ERKs are activated in larger numbers. Thus, it seems that adrenal proliferation could be at least partly regulated by the ERKs cascade. However, one also has to consider that other mechanisms may be present that can influence ERKs activation and function. Namely, the PKA-dependent expression of MKP-1 and the activation of JNK described previously (Watanabe et al. 1997, Bey et al. 2003, Winnay \& Hammer 2006) are likely to regulate some of the effects induced by ACTH. The possible crosstalk with ERKs activation and function on the adrenal gland needs further studying.

One other interesting aspect has to do with phosphoERKs presence in ZG after ACTH treatment, albeit at lower levels than in ZF and ZR. McNeill et al (1998) reported the presence of the unphosphorylated, inactive forms ERKs in ZG. In this study, we report that ACTH activates ERKs not only in ZF and ZR, but also in ZG. Our present findings support the idea that ACTH also acts on glomerulosa cells by activating ERKs, although one can only speculate as to what their other functions may be. This is not in contradiction with the fact that other adrenal stimulating factors such as 
angiotensin-II and several neuropeptides can also induce ERKs activation in the adrenal ZG (Watanabe et al. 1996, Whitworth et al. 2002, McNeill et al. 2005).

In addition, our results also indicate that $\mathrm{ACTH}$ induces ERKs phosphorylation in endothelial cells. Recently, Thomas et al. (2004) have reported that ACTH is required for adrenocortical vasculature maintenance. Hence, it is likely that ERKs could play an important role in mediating endothelial cell stability and proliferation either directly or by regulating VEGF synthesis as was demonstrated in other systems (Pedram et al. 1998, Jung et al. 1999, Gifford et al. 2004). This could account for the increased vascularization of the adrenal, especially in chronic ACTH treatments.

In summary, our model clearly shows a distinct response of the adrenal to acute or chronic ACTH stimulations. Also, it is possible that activation of ERKs could have more than one role in adrenal function, in parallel with those two peaks of activation. This is partly in agreement to what has been described by Winnay \& Hammer (2006), who showed that ACTH-mediated ERKs activation has a cyclic pattern in short treatments. Our results are also in agreement with the notion that ERKs activation is often dependent on the strength as well as duration of the signal (Murphy et al. 2002, MacKeigan et al. 2005). However, for longer treatments (3 and 15 day groups) the cyclic pattern is no longer observable. This could mean that the response of the adrenal is altered. That is also what happens with corticosterone, since in chronic stimulation it no longer decreases to normal values unlike in acute treatments (even if there is a 24-h interval between the last injection and killing). This is even the case when we normalize corticosterone values for the total number of cells, thus ruling out the possibility that corticosterone increases are due to higher numbers of cells in the adrenal. Therefore, the higher corticosterone measurements must be due to an overall higher production and secretion by adrenals subjected to chronic ACTH treatments.

The elevated phosphoER Ks in endothelial cells of chronic ACTH-treated animals could also partly explain the changes in the vascular bed pattern observed in these situations.

These results may help understand the effects of chronic ACTH elevation and perhaps be used as an animal model of Cushing's disease. It gives us some knowledge of the signalling events by which the adrenal responds to acute and chronic stress conditions. For that purpose, we are currently studying the effects of ERKs activation in the regulation of ACTHmediated adrenal proliferation observed in chronic stimulations a well as the possible role of ERKs in the regulation of corticosterone secretion by altering the activation of the ERKs pathway in vivo.

\section{Acknowledgements}

The authors would like to acknowledge Prof. Henrique Almeida for the helpful contribution to the discussion. The authors would also like to acknowledge Mr Fernando Pinto for technical assistance. The authors declare that there is no conflict of interest that would prejudice the impartiality of this scientific work.

\section{References}

Almeida H, Magalhães MC \& Magalhães MM 1998 Age-related changes in the inner zone of the adrenal cortex of the rat - a morphologic and biochemical study. Mechanisms of Ageing and Development 105 1-18.

Almeida H, Ferreira J \& Neves D 2004 Macrophages of the adrenal cortex: a morphological study of the effects of aging and dexamethasone administration. Annals of the New York Academy of Sciences 1019 135-140.

Barker S, Laird SM, Ho MM, Vinson GP \& Hinson JP 1992 Characterization of a rat adrenocortical inner zone-specific antigen and identification of its putative precursor. Journal of Molecular Endocrinology 9 95-102.

Bey P, Gorostizaga AB, Maloberti PM, Lozano RC, Poderoso C, Maciel FC, Podestá EJ \& Paz C 2003 Adrenocorticotropin induces mitogen-activated protein kinase phosphatase 1 in Y1 mouse adrenocortical tumor cells. Endocrinology 144 1399-1406.

Bicknell AB, Lomthaisong K, Woods RJ, Hutchinson EG, Bennett HP, Gladwell RT \& Lowry PJ 2001 Characterization of a serine protease that cleaves pro-gamma-melanotropin at the adrenal to stimulate growth. Cell 105 903-912.

Cameron MR, Foster JS, Bukovsky A \& Wimalasena J 1996 Activation of mitogen-activated protein kinases by gonadotropins and cyclic adenosine $5^{\prime}$-monophosphates in porcine granulosa cells. Biology of Reproduction $\mathbf{5 5}$ 111-119.

Clark BJ, Ranganathan V \& Combs R 2001 Steroidogenic acute regulatory protein expression is dependent upon post-translational effects of cAMPdependent protein kinase A. Molecular and Cellular Endocrinology 173 183-192.

Cooke BA 1999 Signal transduction involving cyclic AMP-dependent and cyclic AMP-independent mechanisms in the control of steroidogenesis. Molecular and Cellular Endocrinology 151 25-35.

Davis WW \& Garren LD 1968 On the mechanism of action of adrenocorticotropic hormone. Journal of Biological Chemistry 542 5153-5157.

DiBartolomeis MJ \& Jefcoate CR 1984 Characterization of the acute stimulation of steroidogenesis in primary bovine adrenal cortical cell cultures. Journal of Biological Chemistry 259 10159-10167.

Fassnacht M, Hahner S, Hansen IA, Kreutzberger T, Zink M, Adermann K, Jakob F, Troppmair J \& Allolio B 2003 N-terminal proopiomelanocortin acts as a mitogen in adrenocortical tumor cells and decreases adrenal steroidogenesis. Journal of Clinical Endocrinology and Metabolism 88 2171-2179.

Fujita K, Aguilera G \& Catt KJ 1979 The role of cyclic AMP in aldosterone production by isolated zona glomerulosa cells. Journal of Biological Chemistry 254 8567-8574.

Gallo-Payet N \& Payet MD 2003 Mechanism of action of ACTH: beyond cAMP. Microscopy Research and Technique 61 275-287.

Gifford SM, Grummer MA, Pierre SA, Austin JL, Zheng J \& Bird IM 2004 Functional characterization of HUVEC-CS: $\mathrm{Ca}^{2+}$ signaling, ERK $1 / 2$ activation, mitogenesis and vasodilator production. Journal of Endocrinology $182485-499$.

Gutkind JS 1998 The pathways connecting G protein-coupled receptors to the nucleus through divergent mitogen-activated protein kinase cascades. Journal of Biological Chemistry 273 1839-1842.

Gyles SL, Burns CJ, Persaud SJ, Jones PM \& Withehouse BJ 2000 A role for the $\mathrm{p} 42 / \mathrm{p} 44$ isoforms of MAPK in the regulation of steroid secretion from Y1 mouse adrenocortical cells. Endocrine Research 26 579-581.

Gyles SL, Burns CJ, Whitehouse BJ, Sudgen D, Marsh PJ, Persaud SJ \& Jones PM 2001 ERKs regulate cyclic AMP-induced steroid synthesis through transcription of the steroidogenic acute regulatory (StAR) gene. Journal of Biological Chemistry 276 34888-34895.

Imaki T, Naruse M \& Takano K 2004 Adrenocortical hyperplasia associated with ACTH-dependent Cushing's syndrome: comparison of the size of adrenal glands with clinical and endocrinological data. Endocrine Journal $\mathbf{5 1}$ 89-95. 
Johnson GL \& Lapadat R 2002 Mitogen-activated protein kinase pathways mediated by ERK, JNK, and p38 protein kinases. Science 298 1911-1912.

Jung YD, Nakano K, Kiu W, Gallick GE \& Ellis LM 1999 Extracellular signalregulated kinase activation is required for up-regulation of vascular endothelial growth factor by serum starvation in human colon carcinoma cells. Cancer Research 59 4804-4807.

Kimura E, Sonobe MH, Armelin MCS \& Armelin HA 1993 Induction of FOS and JUN proteins by adrenocorticotropin and phorbol ester but not by $3^{\prime}, 5^{\prime}$ - cyclic adenosine monophosphate derivatives. Molecular Endocrinology 7 1463-1471.

Krueger RJ \& Orme-Johnson NR 1983 Acute adrenocorticotropic hormone stimulation of adrenal corticosteroidogenesis. Journal of Biological Chemistry 258 10159-10167.

Le T \& Schimmer BP 2001 The regulation of MAPKs in Y1 mouse adrenocortical tumor cells. Endocrinology 142 4282-4287.

Lehoux J-G, Fleury A \& Ducharme L 1998 The acute effects of adrenocorticotropin on the levels of messenger ribonucleic acid and protein of steroidogenic enzymes in rat adrenal in vivo. Endocrinology 1393913-3922.

Lehoux J-G, Mathieu AM, Lavigne P \& Fleury A 2003 Adrenocorticotropin regulation of steroidogenic acute regulatory protein. Microscopy Research and Techniques 61 288-299.

Lotfi CFP \& Armelin HA 1998 c-Fos is a mediator in mitogenic response to ACTH. Endocrine Research 24 421-424.

Lotfi CFP, Costa ET, Schwindt TT \& Armelin HA 2000 Role of ERK/MAP kinase in mitogenic interaction between ACTH and FGF2 in mouse Y1 adrenocortical tumor cells. Endocrine Research 26 873-877.

MacKeigan JP, Murphy LO, Dimitri CA \& Blenis J 2005 Graded mitogenactivated protein kinase activity precedes switch-like c-Fos induction in mammalian cells. Molecular and Cellular Biology 25 4676-4682.

Manna PR, Chandrala SP, Jo Y \& Stocco DM 2006 cAMP-independent signaling regulates steroidogenesis in mouse Leydig cells in the absence of StAR phosphorylation. Journal of Molecular Endocrinology 37 81-95.

Martinat N, Crepieux P, Reiter E \& Guillou F 2005 Extracellular signalregulated kinases (ERK) 1, 2 are required for luteinizing hormone (LH)induced steroidogenesis in primary Leydig cells and control steroidogenic acute regulatory (StAR) expression. Reproduction, Nutrition, Development $\mathbf{4 5}$ 101-108.

McNeill H, Puddefoot JR \& Vinson GP 1998 MAP kinase in the rat adrenal gland. Endocrine Research 24 373-380.

McNeill H, Whitworth E, Vinson GP \& Hinson JP 2005 Distribution of extracellular signal-regulated protein kinases 1 and 2 in the rat adrenal and their activation by Angiotensin II. Journal of Endocrinology 187 149-157.

McNicol AM 2000 Diseases of the adrenal cortex. Current Diagnostic Pathology 6 171-180.

Mitani F, Mukai K, Myiamoto H, Suematsu M \& Ishimura Y 2003 The undifferentiated cell zone is a stem cell zone in adult rat adrenal cortex. Biochimica et Biophysica Acta 1619 317-324.

Murphy LO, Smith S, Chen RH, Fingar DC \& Blenis J 2002 Molecular interpretation of ERK signal duration by immediate early gene products. Nature Cell Biology 4 556-564.

Neves D, Magalhães MM \& Magalhães MC 2000 Poly-A-rich domains in adrenal cell nuclear matrix after acute and chronic ACTH stimulation: an in situ hybridization study. Cell and Tissue Research 302 81-84.

Paul A, Wilson S, Belham CM, Robinson CJM, Scott PH, Gould GW \& Plevin R 1997 Stress-activated protein kinases: activation, regulation and function. Cellular Signalling 9 403-410.

Pedram A, Razandi M \& Levin ER 1998 Extracellular signal-regulated protein kinase/jun kinase cross-talk underlies vascular endothelial growth factor-induced endothelial cell proliferation. Journal of Biological Chemistry $27326722-26728$.

Pignatelli D, Ferreira J, Vendeira P, Magalhães MC \& Vinson GP 2002 Proliferation of capsular stem cells induced by ACTH in the rat adrenal cortex. Endocrine Research 28 685-693.

Pudney J, Price GM, Whitehouse BJ \& Vinson GP 1984 Effects of chronic ACTH stimulation on the morphology of the rat adrenal cortex. Anatomical Record 210 603-615.

Robinson MJ \& Cobb MH 1997 Mitogen-activated protein kinase pathways. Current Opinion in Cell Biology 9 180-186.

Seelig S \& Sayers G 1973 Isolated adrenal cortex cells: ACTH agonists, partial agonists, antagonists; cyclic AMP and corticosterone production. Archives of Biochemistry and Biophysics 154 230-239.

Sewer MB \& Waterman MR 2003 ACTH modulation of transcription factors responsible for steroid hydroxylase gene expression in the adrenal cortex. Microscopy Research and Technique 61 300-307.

Stork PJS \& Schmitt JM 2002 Crosstalk between cAMP and MAP kinase signalling in the regulation of cell proliferation. Trends in Cell Biology 12 258-266.

Tait JF, Tait SAS, Bell JBG, Hyatt PJ \& Williams BC 1980 Further studies on the stimulation of rat adrenal capsular cells: four types of response. Journal of Endocrinology 87 11-27.

Thomas M, Keramidas M, Monchaux E \& Feige J-J 2004 Dual hormone regulation of endocrine tissue mass and vasculature by adrenocorticotropin in the adrenal cortex. Endocrinology 145 4320-4328.

Vanhoutte P, Barnier J-V, Guibert B, Pagès C, Besson M-J, Hipskind RA \& Caboche J 1999 Glutamate induces phosphorylation of Elk-1 and CREB, along with c-fos activation, via an extracellular signal-regulated kinasedependent pathway in brain slices. Molecular and Cellular Biology 19 136-146.

Vinson GP 2003 Adrenocortical zonation and ACTH. Microscopy Research and Technique 61 227-239.

Volmat V \& Pouysségur J 2001 Spatiotemporal regulation of the p42/p44 MAPK pathway. Biology of the Cell 93 71-79.

Watanabe G, Lee RJ, Albanese C, Rainey WE, Battle D \& Pestell RG 1996 Angiotensin II activation of cyclin D1-dependent kinase activity. Journal of Biological Chemistry 271 22570-22577.

Watanabe G, Pena P, Albanese C, Wilsbacher LD, Young JB \& Pestel RG 1997 Adrenocorticotropin induction of stress-activated protein kinase in the adrenal cortex in vivo. Journal of Biological Chemistry 272 20063-20069.

Whitworth EJ, Hinson JP \& Vinson GP 2002 Neuropeptides and adrenocortical proliferation in vitro. Endocrine Research 28 677-681.

Winnay JN \& Hammer GD 2006 Adrenocorticotropic hormone-mediated signaling cascades coordinate a cyclic pattern of steroidogenic factor-1 dependent transcriptional activation. Molecular Endocrinology 20 $147-166$

Wu C-H, Chen Y-F, Wang J-Y, Hsieh C-S, Lian S-T, Shin S-J \& Lin S-R 2002 Mutant K-ras oncogene regulates steroidogenesis of normal human adrenocortical cells by the RAF-MEK-MAPK pathway. British Journal of Cancer 87 1000-1005.

Received in final form 4 December 2006

Accepted 12 December 2006

Made available online as an Accepted Preprint 27 December 2006 